\title{
Control of brown adipose tissue glucose and lipid metabolism by PPAR $\gamma$
}

\author{
William T. Festuccia ${ }^{1}$, Pierre-Gilles Blanchard ${ }^{2}$ and Yves Deshaies ${ }^{2}$ * \\ 1 Department of Physiology and Biophysics, Institute of Biomedical Sciences, University of São Paulo, São Paulo, Brazil \\ 2 Department of Medicine, Quebec Heart and Lung Institute, Quebec, OC, Canada
}

\author{
Edited by: \\ Patrick Seale, University of \\ Pennsylvania, USA \\ Reviewed by: \\ Miguel Lopez, University of Santiago \\ de Compostela, Spain \\ Takahiro Shimizu, Kochi University, \\ Japan \\ *Correspondence: \\ Yves Deshaies, Quebec Heart and \\ Lung Institute, Pavillon Margeritte \\ d'Youville Y3110, 2725 Chemin \\ Sainte-Foy, Quebec, QC, Canada G1V \\ $4 G 5$. \\ e-mail:yves.deshaies@fmed.ulaval.ca
}

Brown adipose tissue (BAT) non-shivering thermogenesis impacts energy homeostasis in rodents and humans. Mitochondrial uncoupling protein 1 in brown fat cells produces heat by dissipating the energy generated by fatty acid and glucose oxidation. In addition to thermogenesis and despite its small relative size, sympathetically activated BAT constitutes an important glucose, fatty acid, and triacylglycerol-clearing organ, and such function could potentially be used to alleviate dyslipidemias, hyperglycemia, and insulin resistance. To date, chronic sympathetic innervation and peroxisome proliferator-activated receptor (PPAR) $\gamma$ activation are the only recognized inducers of BAT recruitment. Here, we review the major differences between these two BAT inducers in the regulation of lipolysis, fatty acid oxidation, lipid uptake and triacylglycerol synthesis, glucose uptake, and de novo lipogenesis. Whereas BAT recruitment through sympathetic drive translates into functional thermogenic activity, PPAR $\gamma$-mediated recruitment is associated with a reduction in sympathetic activity leading to increased lipid storage in brown adipocytes. The promising therapeutic role of BAT in the treatment of hypertriglyceridemic and hyperglycemic conditions is also discussed.

Keywords: rosiglitazone, PPARy, brown adipose tissue, sympathetic nervous system, glucose metabolism, lipid metabolism, obesity

\section{INTRODUCTION}

Brown adipose tissue (BAT) plays an important role in rodent whole body energy homeostasis due to its extreme ability under demand to dissipate energy as heat (Cannon and Nedergaard, 2004). This process, known as non-shivering thermogenesis, is positively regulated through norepinephrine (NE) release by the sympathetic nerves that densely innervate BAT. Upon sympathetic activation, NE interacts with $\beta_{3}$ adrenergic receptors leading to lipase-mediated triacylglycerol (TAG) hydrolysis. Whereas lipolysis-derived glycerol is recycled back to TAG by glycerokinase (GyK; Festuccia et al., 2003a), lipolysis-derived fatty acids (FA) are directed to the mitochondria where they either undergo oxidation or allosterically activate uncoupling protein (UCP) 1 . Active UCP1 dissipates the proton gradient across the inner mitochondrial membrane, thus leading to heat production at the expense of ATP synthesis. FA derived from intracellular TAG hydrolysis are the only activators of UCP1 and mitochondrial uncoupling as evidenced by defective thermogenesis in mice lacking lipolytic adipose triglyceride lipase (ATGL; Zimmermann et al., 2004). Therefore, maintenance of intracellular TAG stores is essential for BAT non-shivering thermogenesis as supported by the marked increase in BAT TAG synthesis in cold-acclimated rats (Cannon and Nedergaard, 2004; Moura et al., 2005).

In addition to thermogenesis, sympathetic innervation is a major regulator of brown adipocyte proliferation, differentiation, and apoptosis implicated in BAT maintenance and function (Cannon and Nedergaard, 2004). Chronic sympathetic activation not only increases BAT mass by enhancing brown adipocyte proliferation and differentiation and by reducing apoptosis (Bronnikov et al., 1999; Lindquist et al., 2000; Cannon and Nedergaard, 2004), but also stimulates mitochondrial biogenesis and the expression of the thermogenic proteins UCP1 and peroxisome proliferatoractivated receptor (PPAR) coactivator-1 (PGC-1) $\alpha$ (Puigserver et al., 1998; de Jesus et al., 2001; Silva, 2006) amplifying BAT capacity to produce heat (Cannon and Nedergaard, 2004).

Chronic sympathetic activation was the only recognized inducer of BAT recruitment until the discovery that pharmacological activation of PPAR $\gamma$ also increases BAT mass and UCP1 levels in rodents (Mercer and Trayhurn, 1986; Rothwell et al., 1987; Thurlby et al., 1987; Sell et al., 2004). PPAR $\gamma$ is a nuclear receptor highly expressed in BAT that acts as a master transcriptional regulator of brown adipocyte differentiation required for tissue development, function, and survival (Barak et al., 1999; He et al., 2003; Imai et al., 2004; Gray et al., 2006; Duan et al., 2007; Petrovic et al., 2008). Remarkably, however, PPAR $\gamma$-mediated BAT recruitment is associated with a reduction in BAT sympathetic activity and thyroid status, which seems to prevent the translation of a high thermogenic capacity (BAT mass and UCP1 content) into increased functional thermogenic activity (Festuccia et al., 2008). Despite being significantly reduced, the residual sympathetic tone remaining under pharmacological PPAR $\gamma$ activation modulates major components of PPAR $\gamma$-mediated BAT recruitment, including maximal UCP1 expression (Festuccia et al., 2010). 
Concomitantly with the upregulation of the thermogenic potential of BAT, PPAR $\gamma$ activation improves its ability to clear and store circulating lipids as TAG, which is associated with important changes in tissue glucose uptake and utilization. In the past few years we have worked toward elucidating the mechanisms whereby PPAR $\gamma$ agonism impacts BAT glucose and lipid metabolism. In the following sections we discuss the major findings of these studies, their integration into current knowledge on the mechanisms of action of PPAR $\gamma$ ligands, and future directions of this research area. Finally, the promising therapeutic role of BAT as an energy expending tissue for obesity treatment and as a glucose and lipid-clearing organ in the treatment of hyperglycemic and hypertriglyceridemic conditions are addressed.

\section{BROWN ADIPOCYTE LIPOLYSIS}

Intracellular lipolysis of TAG to FA and glycerol is directly related to BAT thermogenic function such that no thermogenesis can be evoked without activation of lipolysis (Cannon and Nedergaard, 2004). TAG hydrolysis is catalyzed in a stepwise manner by ATGL, hormone-sensitive lipase (HSL), and monoacyglycerol lipase (MGL), which have preferential hydrolytic activity toward TAG, diacylglycerol, and monoacylglycerol, respectively (Zechner et al., 2009). BAT lipolysis is activated by NE released by sympathetic nerves. NE, through activation of $\beta_{3}$ adrenergic receptors and associated adenylyl cyclase, raises cAMP that allosterically interacts and activates protein kinase $\mathrm{A}$, which in turn phosphorylates HSL, thereby inducing its translocation to lipid droplets and increasing its hydrolytic activity.

Peroxisome proliferator-activated receptor $\gamma$ activation by the agonist rosiglitazone is associated with an upregulation of BAT lipolytic machinery due to increased expression of ATGL and its partner CGI-58 and MGL (Festuccia et al., 2010). Similar to the upregulation of thermogenic genes, such higher lipase levels are not translated into higher functional lipolytic rates due to the inhibition by rosiglitazone of BAT sympathetic activity (Festuccia et al., 2008). In addition, the release of lipolysis-derived FA from BAT is counteracted by their intracellular recycling and re-esterification back to TAG, a process that strongly depends upon the generation of glycerol-3-phosphate (G3P), which is markedly stimulated by rosiglitazone, as discussed below (Festuccia et al., 2009b).

\section{BROWN ADIPOCYTE FATTY ACID OXIDATION AND MITOCHONDRIAL BIOGENESIS}

Brown adipose tissue has a marked ability to oxidize FA and glucose as a consequence of high tissue mitochondrial number and oxidative enzymes content. Such high oxidative capacity is translated into high rates of oxygen consumption, making BAT the major body oxygen-consuming organ in situations of active non-shivering thermogenesis (Cannon and Nedergaard, 2004). Lipolysis-derived FA are the preferred substrates oxidized in BAT, providing most of the energy converted to heat by UCP1mediated mitochondrial uncoupling (Cannon and Nedergaard, 2004). Acutely, sympathetic activation upregulates BAT FA oxidation by increasing lipolysis and intracellular FA availability, and by enhancing carnitine palmitoyl transferase (CPT) 1 activity and FA entry into the mitochondria (Cannon and Nedergaard, 2004).
Chronically, sympathetic activation upregulates BAT oxidative capacity by increasing mitochondrial number, an effect mediated by PGC- $1 \alpha$, an adrenergically modulated coregulator of nuclear receptor function implicated in mitochondrial biogenesis (Puigserver et al., 1998). In contrast to sympathetic activation, PPAR $\gamma$ activation in vivo is not associated with changes in BAT mitochondrial number and PGC-1 $\alpha$ expression (Festuccia et al., 2010). In brown adipocytes in vitro, rosiglitazone does not affect PGC- $1 \alpha$ expression but increases mitochondrial number and CPT1 content, such effects being translated into higher oxygen consumption only in the presence of NE (Petrovic et al., 2008). Altogether, these findings indicate a major role of the sympathetic nervous system to enhance brown adipocyte mitochondrial function, such action being potentiated by PPAR $\gamma$ activation.

\section{BROWN ADIPOCYTE LIPID UPTAKE AND TRIACYLGLYCEROL SYNTHESIS}

Circulating chylomicron- and very-low-density lipoprotein (VLDL)-bound TAG are the major source of FA incorporated into BAT, a process catalyzed by the endothelium-bound enzyme lipoprotein lipase (LPL), which hydrolyzes circulating TAG to FA and monoacylglycerol for BAT uptake. BAT is a major plasma lipid-clearing organ in rodents and therefore a strong modulator of triglyceridemia (Festuccia et al., 2009b; Laplante et al., 2009; Bartelt et al., 2011). Cold exposure, for example, markedly activates BAT lipid clearance and LPL activity, thus inducing hypotriglyceridemia despite increased liver VLDL-TAG secretion (Mantha and Deshaies, 1998; Moura et al., 2005; Bartelt et al., 2011). In addition, BAT lipid uptake in rodents exposed to cold is favored by an increase in the membrane FA transporter FAT/CD36 (Bartelt et al., 2011).

Similar to cold exposure, pharmacological PPAR $\gamma$ activation in rodents markedly increases BAT TAG clearance and LPL activity, such effects contributing to the hypotriglyceridemic action of PPAR $\gamma$ agonists (Festuccia et al., 2009b; Laplante et al., 2009). Most of the FA taken up by brown adipocytes are directed toward TAG synthesis, a process strongly dependent upon G3P availability (discussed below) and the stepwise enzymatic acylation of its carbon backbone. Initial G3P acylation to lysophosphatidic acid is catalyzed by glycerol-3-phosphate acyltransferase (GPAT; Figure 1). Lysophosphatidic acid is then acylated to form phosphatidic acid, which is dephosphorylated to diacylglycerol by phosphatidic acid phosphatase 1 (PAP1, also called lipin) and further acylated to TAG by diacylglycerol acyltransferase (DGAT). In addition to TAG clearance and FA uptake, rosiglitazone activates BAT TAG synthesis by stimulating the activities of GPAT and DGAT. Among the GPAT and DGAT isoforms, rosiglitazone specifically increases mRNA levels of GPAT3 and DGAT1, respectively, both located in the endoplasmic reticulum. GPAT3 and DGAT1 expression is markedly upregulated by PPAR $\gamma$ activation in 3T3-L1 adipocyte (Cao et al., 2006; Yen et al., 2008) and in BAT suggesting direct transcriptional regulation, a hypothesis that remains to be tested. Surprisingly, lipin levels and PAP activity are not affected by rosiglitazone in BAT (Festuccia et al., 2009b), in contrast with the marked stimulation of lipin-1 levels in rat white adipose tissue (WAT; Festuccia and Deshaies, 2009; Festuccia et al., 2009a), and that of lipin-1 expression by pioglitazone in WAT of insulin-resistant humans 
(Yao-Borengasser et al., 2006). Noteworthy, PAP specific activity (relative to protein) is 5 to 15 -fold higher in BAT than in WAT under basal conditions (Festuccia et al., 2009a); activation of such abundant lipin-1 in BAT may therefore suffice to accommodate the elevated TAG synthetic flux brought by rosiglitazone without the need to increase lipin expression, as is the case in WAT.

\section{BROWN ADIPOCYTE GLUCOSE UPTAKE AND INTRACELLULAR METABOLISM}

In BAT, glucose is used not only for G3P synthesis (Figure 1), the carbon backbone for FA esterification, and TAG synthesis, and that of FA through de novo lipogenesis, but also for energy generation that supports FA esterification to TAG and other adipocyte functions. Significant amounts of glucose in BAT are also stored as glycogen and converted to lactate by anaerobic glycolysis (Cannon and Nedergaard, 2004). BAT displays very high rates of glucose uptake per unit weight, such that even though BAT makes up only a small fraction of rodent body weight, it can constitute a significant glucose-clearing organ especially under sympathetic activation (Cannon and Nedergaard, 2004). Such high rates of BAT glucose uptake in humans as estimated in vivo by positron emission tomography are close to those seen in cancer, making BAT a confounding factor for tumor diagnosis. BAT sympathetic activation markedly increases glucose uptake by activating the glucose transporter (GLUT) 1(Cannon and Nedergaard, 2004). In contrast to sympathetic activation, however, BAT rates of glucose uptake and GLUT4 mRNA levels are markedly reduced by rosiglitazone. This contrasts with the well-established PPAR $\gamma$ effects on glucose uptake by subcutaneous WAT, skeletal muscle and heart (Zierath et al., 1998) and excludes a likely contribution of BAT to glucose clearance and the in vivo insulin-sensitizing effect of rosiglitazone in rodents.

How rosiglitazone reduces BAT glucose uptake is unknown. It does not seem, however, to involve a direct rosiglitazone effect on BAT as evidenced by the modest increase in glucose uptake and unchanged GLUT4 mRNA levels in isolated brown adipocytes treated with rosiglitazone (Hernandez et al., 2003). Sympathetic innervation, through NE regulation of GLUT1 content and functional activation (Dallner et al., 2006), and insulin, through stimulation of GLUT4 expression and translocation (Teruel et al., 1996), are the major positive regulators of BAT glucose uptake (Cannon and Nedergaard, 2004). It is, therefore, reasonable to suggest that the reduction in both BAT sympathetic drive and plasma insulin levels induced by rosiglitazone (Festuccia et al., 2008) might contribute to reduced BAT glucose uptake.

Likely due to the reduced glucose flux per brown adipocyte, an important consequence of rosiglitazone treatment is a reduction in BAT glycogen content, its synthesis from glucose and the mRNA levels of UDP-linked glucose pyrophosphorylase (UDPGPPL), which generates UDP-linked glucose for glycogen synthesis. BAT stores significant amounts of glycogen that seem to be an important source of glucose during non-shivering thermogenesis as evidenced by the enhanced glycogen utilization in BAT of rats exposed to cold (Farkas et al., 1999; Jakus et al., 2008). During non-shivering thermogenesis, significant

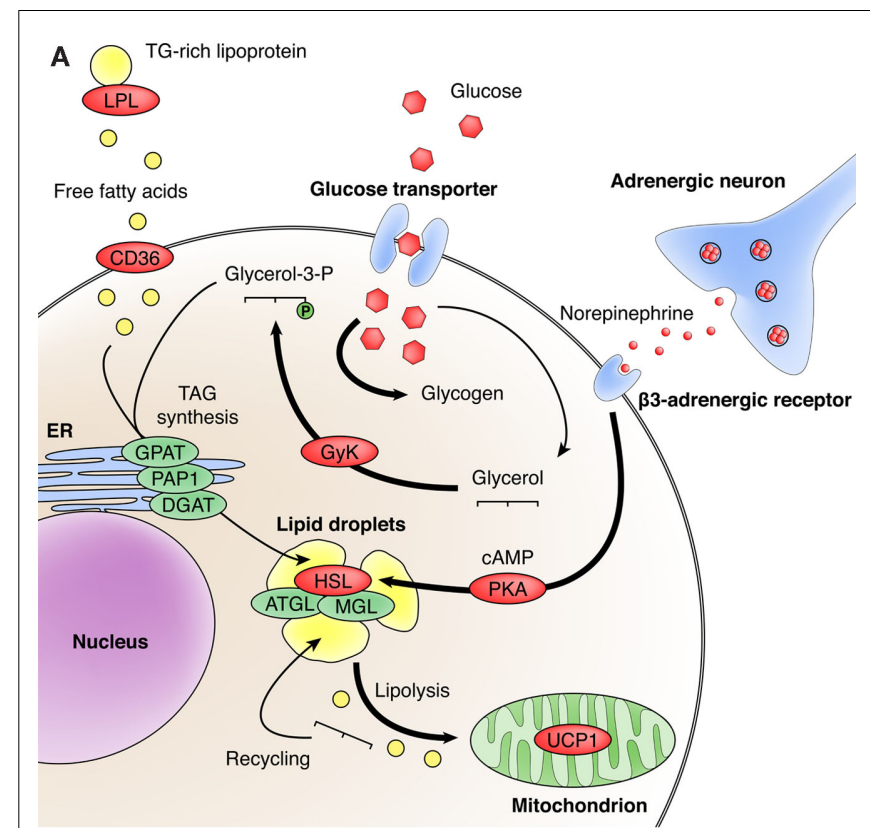

B

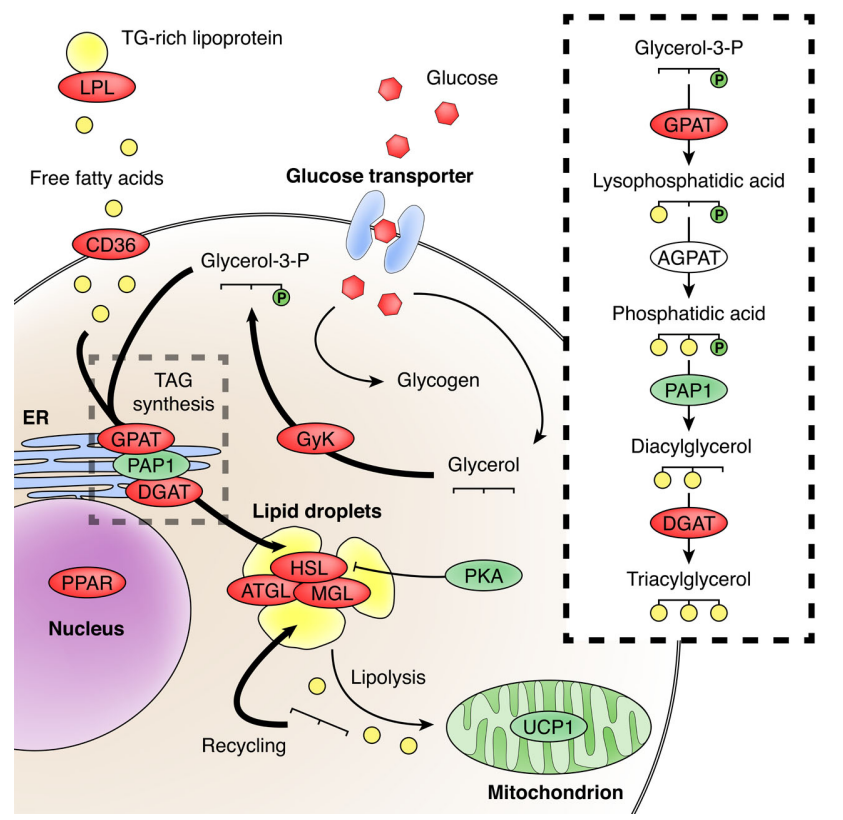

FIGURE 1 | Modulation of brown adipose tissue glucose and lipid metabolism by cold exposure (A) and PPAR $y$ activation (B). Enzymes in red and pathways with thick arrows are activated in response to corresponding stimulus. Abbreviations: AGPAT, acylglycerol3-phosphate-O-acyltransferase; ATGL, adipose triglyceride lipase; CD36, fatty acid translocase; DGAT, diacylglycerol acyltransferase; GPAT, glycerol 3-phosphate acyltransferase; GyK, glycerokinase; HSL, hormone-sensitive lipase; LPL, lipoprotein lipase; MGL, monoacyglycerol lipase; PAP1, phosphatidic acid phosphatase 1; PKA, protein kinase A; UCP1, uncoupling protein 1.

amounts of glucose are converted to lactate by anaerobic glycolysis, producing ATP that might be important in compensating for reduced energy production due to mitochondrial 
uncoupling (Cannon and Nedergaard, 2004). In addition, glucose seems to play a major role in replenishing citric acid cycle intermediates (anaplerosis; Owen et al., 2002), which is very important for keeping elevated levels of FA oxidation (Cannon and Nedergaard, 2004). Thus the reduction in BAT glucose uptake and glycogen content induced by rosiglitazone might have some deleterious consequences in terms of BAT thermogenic activity.

\section{BROWN ADIPOCYTE G3P GENERATION}

TAG synthesis depends on the intracellular levels of G3P. Because adequate levels of TAG for lipolysis and FA production are directly related to BAT thermogenic function, the generation of G3P is maintained under strict control.

The enhanced BAT FA storage induced by PPAR $\gamma$ activation is associated with a marked increase in TAG-glycerol synthesis estimated with the ${ }^{3} \mathrm{H}_{2} \mathrm{O}$ technique, suggesting an increase in G3P generation by short glycolysis and glyceroneogenesis (Festuccia et al., 2009b). Indeed, glucose incorporation into TAG-glycerol in vitro and phosphoenolpyruvate carboxykinase (PEPCK) activity, a key glyceroneogenesis enzyme, are significantly increased by rosiglitazone (Festuccia et al., 2009b). Rosiglitazone also increases BAT GyK activity, which generates G3P by direct phosphorylation of glycerol taken up from the circulation or recycled from TAG hydrolysis. Remarkably, rosiglitazone upregulates GyK even under reduced BAT sympathetic drive (Festuccia et al., 2008), a major positive regulator of BAT GyK (Kawashita et al., 2002; Festuccia et al., 2003a). Acclimation to cold and now PPAR $\gamma$ agonism are to date the sole known situations in which all three possible sources of G3P are concomitantly stimulated in BAT (Festuccia et al., 2003a,b; Moura et al., 2005). Both these situations have in common a marked increase in BAT LPL activity and FA flux, which further illustrates the importance of PPAR $\gamma$ in controlling FA esterification and TAG synthesis.

\section{BAT DE NOVO FATTY ACID SYNTHESIS}

Along with TAG generation, BAT de novo synthesis of FA is activated in thermogenic conditions such as cold exposure and sympathetic stimulation of BAT (Minokoshi et al., 1988; Yu et al., 2002; Moura et al., 2005). Increased de novo lipogenesis can be considered as an attempt to maintain TAG levels for subsequent hydrolysis and thermogenesis activation. Rosiglitazone-mediated PPAR $\gamma$ activation, however, is not associated with changes in the rates of BAT de novo FA synthesis as estimated in vivo by the ${ }^{3} \mathrm{H}_{2} \mathrm{O}$ technique. This strongly suggests that most of the FA used for TAG synthesis upon PPAR $\gamma$ activation are preformed, likely originating from LPL-mediated hydrolysis of lipoprotein-TAG and albumin-bound non-esterified FA, or recycled from local lipolysis.

\section{PERSPECTIVES}

The recent finding of significant amounts of physiologically active BAT in adult humans (Nedergaard et al., 2007) has renewed attention toward the potential implication of this tissue in metabolic homeostasis. Despite its small contribution to whole body weight ( $\sim 2 \%$ in rodents), BAT has the unique and extraordinary ability on demand to release energy from FA and glucose oxidation as heat by non-shivering thermogenesis. During maximal activation in rodents, BAT is the most oxygen-consuming organ of the body, producing a considerable amount of heat through markedly enhanced FA and glucose oxidation (Cannon and Nedergaard, 2004). Thus BAT can potentially constitute a significant glucose, FA, and TAG-clearing organ especially under sympathetic activation, with possible implications in the treatment of dyslipidemias, hyperglycemia, and insulin resistance. In this regard, pharmacological PPAR $\gamma$ activation emerged as an interesting approach to recruit BAT alternatively to sympathetic activation (Festuccia et al., 2008; Petrovic et al., 2008). PPAR $\gamma$ agonists markedly increase rodent BAT mass and its ability to take up and store FA as TAG. In rodents, BAT significantly contributes to the marked hypolipidemic effects (hypotriglyceridemia and reduced plasma non-esterified FA) of PPAR $\gamma$ agonists (Laplante et al., 2007, 2009). The marked ability of BAT to synthesize TAG under PPAR $\gamma$ activation is related to enhanced generation of G3P and GPAT and DGAT activities. An equivalent activation of BAT TAG synthesis is only seen during cold exposure (Moura et al., 2005), the sole difference being that, under this condition of increased sympathetic activity, newly synthesized TAG is rapidly hydrolyzed to supply FA for thermogenesis, whereas under PPAR $\gamma$ agonism TAG is stored in BAT, probably as a consequence of reduced tissue sympathetic drive. In contrast to lipids, however, BAT glucose uptake does not directly contribute to the improvement in systemic glucose homeostasis induced by rosiglitazone. In fact, glucose uptake per brown adipocyte is reduced by rosiglitazone, in striking contrast with the effects of the agonist in WAT and muscle.

In view of the adverse consequences of pharmacological PPAR $\gamma$ activation such as fluid retention, weight gain, congestive heart failure (Nesto et al., 2003; Lago et al., 2007; Singh et al., 2007), and osteopenia (Kahn et al., 2008) that currently limit the clinical use of PPAR $\gamma$ agonists as insulin sensitizers, progress is being made toward the development of selective PPAR $\gamma$ modulators (SPPARMs). The main goal is to develop SPPARMs that maintain the beneficial effects of PPAR $\gamma$ activation on insulin sensitivity and BAT recruitment without the complications linked with full $\operatorname{PPAR} \gamma$ activation.

It is clear, however, that full PPAR $\gamma$ activation is not an efficient strategy to increase BAT thermogenesis and glucose uptake without the concomitant activation of tissue sympathetic activity. An ideal SPPARM would recruit BAT without interfering with basal sympathetic activity, thus enabling functional thermogenic activity. Efficient PPAR $\gamma$ activation could represent an attractive strategy to augment BAT thermogenic capacity and sensitivity to sympathetic stimulation, thus reducing the dosage of $\beta$-adrenergic agonists needed to functionally turn on thermogenesis. Further research is clearly needed to elucidate the best strategy to explore the fascinating potential of BAT as an energy dissipating and lipidand glucose-clearing organ.

\section{ACKNOWLEDGMENTS}

We acknowledge the financial support of the Canadian Institutes of Health Research to Pierre-Gilles Blanchard (Ph. D. fellowship) and Yves Deshaies (operating grant) and Fundação de Amparo à Pesquisa do Estado de São Paulo to William Festuccia (FAPESP Processes 2009/15354-7 and 2010/19018-9). 


\section{REFERENCES}

Barak, Y., Nelson, M. C., Ong, E. S., Jones, Y. Z., Ruiz-Lozano, P., Chien, K. R., Koder, A., and Evans, R. M. (1999). PPAR gamma is required for placental, cardiac, and adipose tissue development. Mol. Cell 4, 585-595.

Bartelt, A., Bruns, O. T., Reimer, R., Hohenberg, H., Ittrich, H., Peldschus, K., Kaul, M. G., Tromsdorf, U. I., Weller, H., Waurisch, C., Eychmuller, A., Gordts, P. L., Rinninger, F., Bruegelmann, K., Freund, B., Nielsen, P., Merkel, M., and Heeren, J. (2011). Brown adipose tissue activity controls triglyceride clearance. Nat. Med. 17, 200-205.

Bronnikov, G., Bengtsson, T., Kramarova, L., Golozoubova, V., Cannon, B., and Nedergaard, J. (1999). Betal to beta3 switch in control of cyclic adenosine monophosphate during brown adipocyte development explains distinct betaadrenoceptor subtype mediation of proliferation and differentiation. Endocrinology 140, 4185-4197.

Cannon, B., and Nedergaard, J. (2004). Brown adipose tissue: function and physiological significance. Physiol. Rev. 84, 277-359.

Cao, J., Li, J. L., Li, D., Tobin, J. F., and Gimeno, R. E. (2006). Molecular identification of microsomal acyl-CoA:glycerol-3-phosphate acyltransferase, a key enzyme in de novo triacylglycerol synthesis. Proc. Natl. Acad. Sci. U.S.A. 103, 19695-19700.

Dallner, O. S., Chernogubova, E., Brolinson, K. A., and Bengtsson, T. (2006). Beta3-adrenergic receptors stimulate glucose uptake in brown adipocytes by two mechanisms independently of glucose transporter 4 translocation. Endocrinology 147, 5730-5739.

de Jesus, L. A., Carvalho, S. D., Ribeiro, M. O., Schneider, M., Kim, S. W., Harney, J. W., Larsen, P. R., and Bianco, A. C. (2001). The type 2 iodothyronine deiodinase is essential for adaptive thermogenesis in brown adipose tissue. J. Clin. Invest. 108, 1379-1385.

Duan, S. Z., Ivashchenko, C. Y., Whitesall, S. E., D'alecy, L. G., Duquaine, D. C., Brosius, F. C. III., Gonzalez, F. J., Vinson, C., Pierre, M. A., Milstone, D. S., and Mortensen, R. M. (2007). Hypotension, lipodystrophy, and insulin resistance in generalized PPARgamma-deficient mice rescued from embryonic lethality. J. Clin. Invest. 117, 812-822.

Farkas, V., Kelenyi, G., and Sandor, A. (1999). A dramatic accumulation of glycogen in the brown adipose tissue of rats following recovery from cold exposure. Arch. Biochem. Biophys. 365, 54-61.

Festuccia, W. T., Blanchard, P. G., Richard, D., and Deshaies, Y. (2010). Basal adrenergic tone is required for maximal stimulation of rat brown adipose tissue UCP1 expression by chronic PPAR-gamma activation. Am. J. Physiol. Regul. Integr. Comp. Physiol. 299, R159-R167.

Festuccia, W. T., Blanchard, P. G., Turcotte, V., Laplante, M., Sariahmetoglu, M., Brindley, D. N., and Deshaies, Y. (2009a). Depot-specific effects of the PPAR \{gamma\} agonist rosiglitazone on adipose tissue glucose uptake and metabolism. J. Lipid Res. 50, 1185-1194.

Festuccia, W. T., Blanchard, P. -G., Turcotte, V., Laplante, M., Sariahmetoglu, M., Brindley, D. N., Richard, D., and Deshaies, Y. (2009b). The $\operatorname{PPAR}\{\gamma\}$ agonist rosiglitazone enhances rat brown adipose tissue lipogenesis from glucose without altering glucose uptake. Am. J. Physiol. Regul. Integr. Comp. Physiol. 296, R1327-R1335.

Festuccia, W. T., and Deshaies, Y. (2009). Depot specificities of PPAR gamma ligand actions on lipid and glucose metabolism and their implication in PPAR gamma-mediated body fat redistribution. Clin. Lipidol. 4, 633-642.

Festuccia, W. T., Guerra-Sa, R., Kawashita, N. H., Garofalo, M. A., Evangelista, E. A., Rodrigues, V., Kettelhut, I. C., and Migliorini, R. H. (2003a). Expression of glycerokinase in brown adipose tissue is stimulated by the sympathetic nervous system. Am. J. Physiol. Regul. Integr. Comp. Physiol. 284, R1536-R1541.

Festuccia, W. T., Kawashita, N. H., Garofalo, M. A., Moura, M. A., Brito, S. R., Kettelhut, I. C., and Migliorini, R. H. (2003b). Control of glyceroneogenic activity in rat brown adipose tissue. Am. J. Physiol. Regul. Integr. Comp. Physiol. 285, R177-R182.

Festuccia, W. T., Oztezcan, S., Laplante, M., Berthiaume, M., Michel, C., Dohgu, S., Denis, R. G., Brito, M. N., Brito, N. A., Miller, D. S., Banks, W. A., Bartness, T. J., Richard, D., and Deshaies, Y. (2008). Peroxisome proliferatoractivated receptor- $\gamma$-mediated positive energy balance in the AT is associated with reduced sympathetic drive to adipose tissues and thyroid status. Endocrinology 149, 2121-2130.

Gray, S. L., Dalla Nora, E., Backlund, E. C., Manieri, M., Virtue, S., Noland, R. C., O'rahilly, S.,
Cortright, R. N., Cinti, S., Cannon, B., and Vidal-Puig, A. (2006). Decreased brown adipocyte recruitment and thermogenic capacity in mice with impaired peroxisome proliferator-activated receptor (P465L PPARgamma) function. Endocrinology 147, 5708-5714.

He, W., Barak, Y., Hevener, A., Olson, P., Liao, D., Le, J., Nelson, M., Ong, E., Olefsky, J. M., and Evans, R. M. (2003). Adipose-specific peroxisome proliferator-activated receptor $\gamma$ knockout causes insulin resistance in fat and liver but not in muscle. Proc. Natl. Acad. Sci. U.S.A. 100, 15712-15717.

Hernandez, R., Teruel, T., and Lorenzo, M. (2003). Rosiglitazone produces insulin sensitisation by increasing expression of the insulin receptor and its tyrosine kinase activity in brown adipocytes. Diabetologia 46, 1618-1628.

Imai, T., Takakuwa, R., Marchand, S., Dentz, E., Bornert, J. M., Messaddeq, N., Wendling, O., Mark, M., Desvergne, B., Wahli, W., Chambon, P., and Metzger, D. (2004). Peroxisome proliferator-activated receptor $\gamma$ is required in mature white and brown adipocytes for their survival in the mouse. Proc. Natl. Acad. Sci. U.S.A. 101, 4543-4547.

Jakus, P. B., Sandor, A., Janaky, T., and Farkas, V. (2008). Cooperation between BAT and WAT of rats in thermogenesis in response to cold, and the mechanism of glycogen accumulation in BAT during reacclimation. J. Lipid Res. 49, 332-339.

Kahn, S. E., Zinman, B., Lachin, J. M., Haffner, S. M., Herman, W. H., Holman, R. R., Kravitz, B. G., Yu, D., Heise, M. A., Aftring, R. P., and Viberti, G. (2008). Rosiglitazone-associated fractures in type 2 diabetes: an analysis from a diabetes outcome progression trial (ADOPT). Diabetes Care 31, 845-851.

Kawashita, N. H., Festuccia, W. T., Brito, M. N., Moura, M. A., Brito, S. R., Garofalo, M. A., Kettelhut, I. C., and Migliorini, R. H. (2002). Glycerokinase activity in brown adipose tissue: a sympathetic regulation? Am. J. Physiol. Regul. Integr. Comp. Physiol. 282, R1185-R1190.

Lago, R. M., Singh, P. P., and Nesto, R. W. (2007). Congestive heart failure and cardiovascular death in patients with prediabetes and type 2 diabetes given thiazolidinediones: a meta-analysis of randomised clinical trials. Lancet 370, 1129-1136.

Laplante, M., Festuccia, W. T., Soucy, G., Blanchard, P. G., Renaud, A., Berger,
J. P., Olivecrona, G., and Deshaies, Y. (2009). Tissue-specific postprandial clearance is the major determinant of PPARgamma-induced triglyceride lowering in the rat. Am. J. Physiol. Regul. Integr. Comp. Physiol. 296, R57-R66.

Laplante, M., Festuccia, W. T., Soucy, G., Gelinas, Y., Lalonde, J., and Deshaies, Y. (2007). Involvement of adipose tissues in the early hypolipidemic action of PPARgamma agonism in the rat. Am. J. Physiol. Regul. Integr. Comp. Physiol. 292, R1408-R1417.

Lindquist, J. M., Fredriksson, J. M., Rehnmark, S., Cannon, B., and Nedergaard, J. (2000). Beta 3- and alpha1-adrenergic Erk1/2 activation is Src- but not Gi-mediated in Brown adipocytes. J. Biol. Chem. 275, 22670-22677.

Mantha, L., and Deshaies, Y. (1998). Beta-adrenergic modulation of triglyceridemia under increased energy expenditure. Am. J. Physiol. 274, R1769-R1776.

Mercer, S. W., and Trayhurn, P. (1986). Effects of ciglitazone on insulin resistance and thermogenic responsiveness to acute cold in brown adipose tissue of genetically obese (ob/ob) mice. FEBS Lett. 195, 12-16.

Minokoshi, Y., Saito, M., and Shimazu, T. (1988). Sympathetic activation of lipid synthesis in brown adipose tissue in the rat. J. Physiol. (Lond.) 398, 361-370.

Moura, M. A., Festuccia, W. T., Kawashita, N. H., Garofalo, M. A., Brito, S. R., Kettelhut, I. C., and Migliorini, R. H. (2005). Brown adipose tissue glyceroneogenesis is activated in rats exposed to cold. Pflugers Arch. 449, 463-469.

Nedergaard, J., Bengtsson, T., and Cannon, B. (2007). Unexpected evidence for active brown adipose tissue in adult humans. Am. J. Physiol. Endocrinol. Metab. 293, E444-E452.

Nesto, R. W., Bell, D., Bonow, R. O., Fonseca, V., Grundy, S. M., Horton, E. S., Le Winter, M., Porte, D., Semenkovich, C. F., Smith, S., Young, L. H., and Kahn, R. (2003). Thiazolidinedione use, fluid retention, and congestive heart failure: a consensus statement from the American Heart Association and American Diabetes Association. Circulation 108, 2941-2948.

Owen, O. E., Kalhan, S. C., and Hanson, R. W. (2002). The key role of anaplerosis and cataplerosis for citric acid cycle function. J. Biol. Chem. 277, 30409-30412. 
Petrovic, N., Shabalina, I. G., Timmons, J. A., Cannon, B., and Nedergaard, J. (2008). Thermogenically competent nonadrenergic recruitment in brown preadipocytes by a PPARgamma agonist. Am. J. Physiol. Endocrinol. Metab. 295, E287-E296.

Puigserver, P., Wu, Z., Park, C. W., Graves, R., Wright, M., and Spiegelman, B. M. (1998). A cold-inducible coactivator of nuclear receptors linked to adaptive thermogenesis. Cell 92, 829-839.

Rothwell, N. J., Stock, M. J., and Tedstone, A. E. (1987). Effects of ciglitazone on energy balance, thermogenesis and brown fat activity in the rat. Mol. Cell. Endocrinol. 51, 253-257.

Sell, H., Berger, J. P., Samson, P., Castriota, G., Lalonde, J., Deshaies, Y., and Richard, D. (2004). Peroxisome proliferator-activated receptor $\gamma$ agonism increases the capacity for sympathetically mediated thermogenesis in lean and ob/ob mice. Endocrinology 145, 3925-3934.

Silva, J. E. (2006). Thermogenic mechanisms and their hormonal regulation. Physiol. Rev. 86, 435-464.

Singh, S., Loke, Y. K., and Furberg, C. D. (2007). Long-term risk of cardiovascular events with rosiglitazone: a meta-analysis. JAMA 298, 1189-1195.

Teruel, T., Valverde, A. M., Benito, M. and Lorenzo, M. (1996). Insulin-like growth factor I and insulin induce adipogenic-related gene expression in fetal brown adipocyte primary cultures. Biochem. J. 319(Pt 2), 627-632.

Thurlby, P. L., Wilson, S., and Arch, J. R. (1987). Ciglitazone is not itself thermogenic but increases the potential for thermogenesis in lean mice. Biosci. Rep. 7, 573-577.

Yao-Borengasser, A., Rasouli, N., Varma, V., Miles, L. M., Phanavanh, B., Starks, T. N., Phan, J., Spencer, H. J. III., Mcgehee, R. E. Jr., Reue, K., and Kern, P. A. (2006). Lipin expression is attenuated in adipose tissue of insulin-resistant human subjects and increases with peroxisome proliferator-activated receptor $\gamma$ activation. Diabetes 55, 2811-2818.

Yen, C. L., Stone, S. J., Koliwad, S., Harris, C., and Farese, R. V. Jr. (2008). Thematic review series: glycerolipids. DGAT enzymes and triacylglycerol biosynthesis. J. Lipid Res. 49, 2283-2301.

Yu, X. X., Lewin, D. A., Forrest, W., and Adams, S. H. (2002). Cold elicits the simultaneous induction of fatty acid synthesis and betaoxidation in murine brown adipose tissue: prediction from differential gene expression and confirmation in vivo. FASEB J. 16, 155-168.

Zechner, R., Kienesberger, P. C., Haemmerle, G., Zimmermann, R., and Lass, A. (2009). Adipose triglyceride lipase and the lipolytic catabolism of cellular fat stores. J. Lipid Res. 50, 3-21.

Zierath, J. R., Ryder, J. W., Doebber, T., Woods, J., Wu, M., Ventre, J., Li, Z., Mccrary, C., Berger, J., Zhang, B., and Moller, D. E. (1998). Role of skeletal muscle in thiazolidinedione insulin sensitizer (PPARgamma agonist) action. Endocrinology 139, 5034-5041.

Zimmermann, R., Strauss, J. G., Haemmerle, G., Schoiswohl, G., BirnerGruenberger, R., Riederer, M., Lass, A., Neuberger, G., Eisenhaber, F., Hermetter, A., and Zechner, R. (2004). Fat mobilization in adipose tissue is promoted by adipose triglyceride lipase. Science 306, 1383-1386.

Conflict of Interest Statement: The authors declare that the research was conducted in the absence of any commercial or financial relationships that could be construed as a potential conflict of interest.

Received: 30 September 2011; paper pending published: 20 October 2011; accepted: 12 November 2011; published online: 21 December 2011.

Citation: Festuccia WT, Blanchard P-G and Deshaies Y (2011) Control of brown adipose tissue glucose and lipid metabolism by PPAR $\gamma$. Front. Endocrin. 2:84. doi: 10.3389/fendo.2011.00084

This article was submitted to Frontiers in Cellular Endocrinology, a specialty of Frontiers in Endocrinology.

Copyright (c) 2011 Festuccia, Blanchard and Deshaies. This is an open-access article subject to a non-exclusive license between the authors and Frontiers Media $S A$, which permits use, distribution and reproduction in other forums, provided the original authors and source are credited and other Frontiers conditions are complied with. 